the thallium flame in purity of tint, but perhaps of a slightly paler or lighter hue, and it remained uniform like the brightness of these meteors as long as they remained in sight, strongly sugge:ting that either copper, barium, thalium, silver, or some other element giving, in some of its combinations, an intensely green spectrum, was undergoing vivid ignition in their flame. As each of these bright meteors presented a sensibly round disc (the firs: several times brighter, and the second a little brighter than the planet Jupiter), without visible sparks or train of any other colour than that of the head which could give rise to the green colour by the effect of contrast, and yet the green hue was much more distinct than I have noticed in any other meteors, not omitting some bright ones accompanied by very ruddy streaks in the principal displays of November 14, it appears to be a distinguishing feature of the brighter meteors of the annual starshower of December, to which it would be very useful on occasions of its future return to direct particular attention. The meteors of this star-shower are, however, seldom of very con. siderable brightness, and the occurrence of one such during its recent appearance not improbably marked its return during the present year with somewhat more than ordinary intensity. The meteor was simultaneously observed at Glasgow and at New. castle upon Tyne, and its apparent paths among the constellations at those places, directed from the usual radiant point in Gemini, with the duration of its flight, will enable the real height and the speed of motion of one of the principal meteors of the shower to be pretty exactly ascertained.

During many hours of repeated observations under the most favourable conditions of the sky on the nights between the $23^{\text {rd }}$ and the 3 oth ult., and again on the 5th of this month, when observers for the return of the shower of meteors belonging to Biela's comet were on the watch for its appearance at different places in England, Scotland and Ireland, the reports of their observations which have hitherto been communicated to the Luminous Meteor Committee of the British Assuciation have been entirely negative, scarcely a single meteor of the few which were observed being recognised as belonging to the well-known radiantpoint of the shower, which was so conspicuous last year in Andromeda. At various times during the night of the 27 th of November itself, when the sky was generally clear, no meteors of this description were visible, and their absence on all the other nights when the state of the sky permitted a watcil to be kept for them scarcely leaves any reasonable grounds for the supposition that even a comparatively insignificant return of last year's meteor-showers of the 24th and 27th of November has this year been visible in England on the same or on any very nearly adjacent dates.

Newcastle-on-Tyne

\section{Meteor Shower}

From the reported weather in England it seems improbable that the Geminid meteor shower was well observed in England, and as the return was rather above the average a few particulars of what was seen here may at least be interesting.

The nights of the Ioth and $x$ ith, when the watch was kept, were exceedingly clear. Except for a quarter of an hour at the commencement of the first watch there was only one observer, then there were two. The position taken was a window, N.E., whence all was visible from about $3^{\circ}$ from the zenith to the hills opposite (perhaps $10^{\circ}$ or $15^{\circ}$ ), behind which only one meteor disappeared, whilst only one was noticed whose course was part hidden by the roof. The average per hour on the $\mathbf{1}_{2}^{1}$ hours' watch on the roth must have been about 38 , and on the 2 hours' watch on the $I$ Ith, 6o. But the rate in the second hour was much in excess of the first; taking the two thus the result is, from 10-II, about 30 , from II-I2 about 88 . In all probability the rate would have not been much below in the morning hours, but having a cold I did not stop longer.

The brightness was, I think, rather below the average, but as tabulated it was as follows:-

\begin{tabular}{|c|c|c|c|}
\hline & & & \\
\hline Bright as & Jup & & \\
\hline$" 9$ & $\mathrm{I} \mathrm{ma}$ & agn. $*$ & \\
\hline$"$ & 2 & 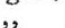 & I7 \\
\hline$"$ & 3 & ", & 1 \\
\hline ", & 4 & ", & 2 \\
\hline 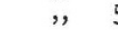 & 5 & ", & \\
\hline
\end{tabular}

A comparison with the radiant points in Mr. R. P. Grey's list makes it seem that the meteors were distributed over at least nine, and that two of these are ones not included by him. Of these one seems pretty certainly fixed about R.A. $57^{\circ} \mathrm{N} .86^{\circ}$, and to this I have assigned I4 on the two nights. The other is more doubtful, two nearly parallel meteors appeared on the Ioth, opposite in direction to the others ; their point may be about R.A. $275^{\circ}$ N. $\delta .60^{\circ}$.

An apparent discrepancy in the total seen and the tabulated numbers is explained by the fact that some meteors were not well enough seen to be entered. But on the regular watch of the Irth I had the unusual success of entering every one seen, in consequence I believe of the position I had assumed, i.e. seeing less than half the heavens and lying on my back. Several cases of almost, or perfectly, simultaneous meteors appeared, but of these only 4 pairs were from the same radiant.

Heidelberg, Dec. 16 J. EdMund Clark

\section{THE LATE PROFESSOR DE LA RIVE}

GWITZERLAND has in one month been shorn of two of her most distinguished ornaments. De La Rive and Agassiz have died within a fortnight of each other, and the "Académie des Sciences" has thus been deprived in the same month of a fourth of its Foreign Associates. Agassiz will no doubt find, both in Switzerland and America, more than one pen competent to describe his labours in the field of science; but a few lines on the life, and researches of de la Rive are due to this distinguished philosopher, and will be read with interest in this country, which he has often visited, and in which he had many friends.

Born at Geneva in $180 \mathrm{I}$, of an old family closely connected with Cavour, Auguste de la Rive inherited from his father the love of science in general, and more especially of electricity. After going through the usual course of studies with brilliant success, he was, at the early age of twenty-two, called to the Chair of Natural Philosophy in the Academy of Geneva, and took his seat amongst the distinguished men of that city.

Although de la Rive devoted his time principally to the study of the different branches of electricity and their numerous applications, his acquirements were not limited to that department of science. During the earlier part of his career the subject of specific heat, more particularly applied to gases, and a series of experiments on the temperature of the crust of the earth, were published by him conjointly with a friend and colleague. But electricity remained his favourite study to the end of his life. The treatise he published between the years I853 and 1858, in three large octavo volumes on the subject of electricity, translated into English by $\mathrm{Mr}$. C. Walker, F.R.S., and the numerous original articles which appeared in the well-known monthly journal, Les Archives 'd'Electricité, for many years under the direction of de la Rive, afford ample proof of the extent of his information on all subjects connected with his favourite pursuit. His original memoirs on electro-dynamics, magnetism, the connection of magnetism with electricity, the nature of the voltaic arc, and on the propagation of electricity in the interior of bodies, more especially through extremely rarefied media, and others too numerous to be quoted, ensured him a high European reputation, to which was soon added the title of Member or Correspondent of almost every scientific body in Europe. In 1840 he was named Correspondent of the French Académie des Sciences; in 1846, Foreign Member of the Royal Society, and finally in I864 he was elected Foreign Associate of the Académie des Sciences, the highest honour to which a man of science can aspire.

It was de la Rive who first conceived the idea of applying the force of electricity, through the means of alkaline solutions, to the gilding of silver and brass, and 
he thus laid down the groundwork of the principle by which thanks to the practical improvements introduced soon after by Messrs. Elkington and Ruolz, electric gilding has gradually superseded the deleterious process of gilding by mercury. It was on this occasion that the grand prize of 3,000 fr. was awarded to de la Rive by the French Academie des Sciences.

A long and patient study of the phenomena which accompany the aurora borealis, and of their apparent connection, both with the properties exhibited by the flame of the Voltaic arc when under the influence of a magnet, and with the passage of the electric fluid through extremely rarefied gases, gradually led de la Rive to a new theory on the electric origin of the aurora. His theory was illustrated, and to a certain extent rendered plausible, by a series of beautiful experiments, reproducing in the lecture-room, through artificial means, the varied phenomena which characterise the aurora. These experiments were made first at Geneva, and some time after repeated at Paris before some of the most distinguished members of the French Institute.

But de la Rive's acquirements were not limited to science. The noble use he made of his fortune, the wellknown hospitality which rendered his country house near Geneva for nearly forty years a centre of attraction to the most distinguished scientific and literary society of Europe, the high tone of his character, and the many services he rendered his country, more particularly when called upon in 1860 to use the influence of his name and position in obtaining from the English Government an effectual support for Switzerland against the threatened danger of French aggression, have secured to his memory a popularity which will long survive him.

\section{VIVISECTION}

THE advance of culture has brought with it an increased tenderness, and a more solicitous regard for the feelings of others, a regard extending slowly but surely to the feelings of animals also. It is to Science that this advance is mainly due. Only by gaining clear conceptions of natural sequences can men be brought to repress their native tendency to inflict pain as an exertion of power, or to feel ashamed of their thoughtless indifference when they see pain inflicted by others. It is demonstrable that Ignorance has ever been the most potent ally of Cruelty-on the small scale of boys torturing animals, and on the large scale of priests torturing heretics. The boy can only be made to feel that his act is vicious by having a vivid imagination of the fact that the animal organism is constructed like his own, and that the animal suffers as he suffers. The holy inquisitor, or enthroned persecutor, can only be made to see that his attempt to combat heresy by an auto-da-fe, is flagrantly at variance with all psychological experience. If the vast cruelties of persecuting "fanatics" have become intolerable in modern society, it is assuredly from no dogmatic teaching. no insistence on charity and love, but wholly from a moral enlightenment coming with a larger and more accurate understanding of natural sequences.

Not only has Science been a great agent in evolving the sympathies, and creating the intense desire to avoid giving pain, it has also created the means of alleviating pain. Is not the whole skill of the surgeon and the physician devoted to this end? How comes it, then, that physiologists who have to supply the surgeon and physician with accurate data, which they can only reach through Experiment, are supposed to be less sympathetic less careful of the feelings of animals, than other men A candid person would at once admit that this was not so ; would admit that physiologists are quite as unwilling to inflict unnecessary pain as men of other classes. But because Vivisection is one of the branches of physiological Experiment, and because when the details of such vivisections are reported, the public reading these, and wholly unacquainted both with the purpose and the procedure, is shocked at what seems needless cruelty, a cry of indignation naturally escapes, and the experimenter is regarded as indifferent to the sufferings of animals.

Every thinking man will admit that the feeling which prompts this indignant cry is highly laudable, and every man who understands the real case will declare that this feeling is misguided by ignorance. For what is the fact? The fact is, that in the vast majority of experiments no pain is inflicted, the operations that are painful being performed under chloroform, and thus the animal which has undergone an operation which would have killed it, had it not been insensible, awakens from the coma and begins tranquilly eating the food before it, as if nothing but a sleep had gone before! In some cases, indeed, pain is unavoidable ; in some it is part of the phenomenon investigated. But this procedure is not chosen in wantonness, or the thoughtlessness of cruelty. The operation is justified by its purpose. If the tender surgeon inflicts pain, it is to save pain ; if the physiologist inflicts pain, it is to widen knowledge, and thus alleviate pain on a wide scale. This is very different from the pain inflicted for the sake of sport; very different from the measureless misery of wars, inficted to gratify national vanity or commercial greed. The physiologist does not inflict pain for his own pleasure; he oyercomes his repugnance to it, as he overcomes his repugnance to the sights of the amphitheatre and hospital, nerved by a sense of ulterior good.

Here we meet the question raised by "X." whether man is justified in inflicting pain on animals to secure the good of fellow-men? I unhesitatingly answer, Yes. It is quite certain that man does assume and assert supremacy, eating, subduing, and exterminating animals, according to his needs; and I would ask whether human life would be practicable on this globe on other conditions? Why, there is seldom a spade thrust into the earth that does not cut some worm into writhing halyes. If this be excused as a painful necessity, then also must vivisection be excused as a painful necessity; if the one is necessary to food, the other is necessary to knowledge. The physiologist is the judge of the necessity; on him rests the responsibility.

And now a word on the particular experiments which called forth X.'s protest. Obviously, since testing sensibility was the very purpose in view, Prof. Goltz, Prof. Foster, and myself were forced either to forego the inquiry, or to inflict more or less pain, and (if need were) excessive pain. Perhaps $X$. will say that such an inquiry ought not to have been pursued at such a cost. We thought otherwise. The point cannot be argued now; but I would illustrate what has been just said, by informing $X$. that even here anæsthetics were used where they could be used-when I removed the skin from the legs or the body of the frogs, or took out their brains, the animals were wholly insensible; and dreadful as it may seem to read of their limbs being pricked, and burned, we are assured that no pain whatever, not even the feeling of contact, was felt by the frogs.

In conclusion, I would urge upon the opponents of Vivisection, that it would be but fair to credit physiologists with the same repugnance to the infliction of pain as animates all enlightened classes; and to consider that if the repugnance is overcome in the pursuit of physio. logical knowledge, it does not the less exist, nor the less guide their conduct in other cases. For myself, I may be permitted to add that so far from acknowledging indifference to the feelings of animals, my sympathies are un. usually active in the direction of animals; and it was my inability to witness pain which prevented my pursuing the 